

Bioethics Research Library

The Joseph and Rose Kennedy Institute of Ethics

Box 571212, Georgetown University

Washington, DC 20057-1212

202-687-3885; fax: 202-687-8089

bioethics@georgetown.edu

http://bioethics.georgetown.edu

\title{
Vulnerability, Vulnerable Populations, and Policy
}

\author{
Mary C. Ruof \\ December, 2004
}

"Special justification is required for inviting vulnerable individuals to serve as research subjects and, if they are selected, the means of protecting their rights and welfare must be strictly applied."

\section{Guideline 13: Research Involving Vulnerable Persons International Ethical Guidelines for Biomedical \\ Research Involving Human Subjects Council for International Organizations of Medical Sciences (CIOMS) and \\ World Health Organization (WHO) Geneva, Switzerland, 2002}

Within medical research and healthcare certain groups are afforded special protections and services because of their designation as vulnerable. The vulnerable require special justification to participate in human subject research in order to eliminate potential human rights abuses. The Nuremberg Code of 1947 was written in response to the extreme human subject abuses that occurred under the Nazi regime, and, although the intent of the 1947 Code was to protect human rights, rigid voluntary consent requirements deprived some individuals of the right to participate in clinical trials. Recent human research guidelines, such as the CIOMS/WHO guidelines referenced above and the guidelines referenced in Section $\mathrm{V}$ of this Scope Note, attempt to balance both protection from abuse in research and access to new, experimental treatments for the vulnerable. 
Although various protective guidelines stipulate special protections for vulnerable populations, the concept of vulnerability and consequently the criteria designating vulnerable populations remain vague. Precisely who are the vulnerable? The word "vulnerability" stems from the Latin vulnerare, "to wound." (Oxford Encyclopedic English Dictionary 1995). In clinical research, the term vulnerable generally is applied to individuals who are unable to give informed consent or who are susceptible to coercion. The Common Rule (45 CFR 46, Subpart A) includes as vulnerable research subjects: children, prisoners, pregnant women, and persons who are handicapped, mentally disabled, economically disadvantaged, or educationally disadvantaged. Although the Common Rule specifies certain vulnerable categories, the guidelines were not intended to be exclusive, leaving open the interpretation of vulnerability.

In medical research and health policy, vulnerability is an abstract concept that has concrete effects both for those labeled vulnerable and for those not. Clinical researchers, healthcare workers, ethical reviewers, and policymakers must be able to identify vulnerable subjects to establish how healthcare resources will be allocated and who will qualify for special protections and socialized benefits. Attempts to quantify vulnerability in clear, measurable ways have met little if any consensus. As Alexander Morawa (II, 2003, p. 150) states, "There is no single approach to definition of vulnerability. In fact, there is no purposeful categorisation at all."

Difficulties in defining vulnerability have prompted discourse surrounding its utility as a qualifying factor in the allocation of health resources and its appropriateness as a guiding principle in bioethics. Some of the authors cited in this Scope Note argue against the labeling and categorization of vulnerable individuals and populations. "Labeling individuals as 'vulnerable' risks viewing vulnerable individuals as 'others' worthy of pity, a view rarely appreciated" (III, Danis and Patrick 2002, p. 320). The categories of vulnerable groups listed under the Common Rule have been the source of controversy, "for example,

\section{TABLE OF CONTENTS}

Introduction. . . . . . . . . . . . . 1

I. General. . . . . . . . . . . . . . . . . . 3

II. Defining the Concept of Vulnerability. . . . . 4

III. Vulnerability in Healthcare. . . . . . . . . 7

IV. Vulnerability and Medical Research. . . . . . 9

V. Guidelines on Medical Research with

Vulnerable Populations..... . . . . . . . . 12

many find the suggestion that pregnant women are vulnerable to be quite sexist" (IV, DeBruin 2001, p. 7). Instead of creating categories of vulnerable populations, would it not be better to derive an account of just treatment from a just social policy at large that encompasses human vulnerabilities (II, Brock 2002, p. 283).

For some of the authors listed here, the concept of vulnerability is essential to bioethics. Robert Goodin (I, 1985, p. 107) writes that the vulnerability of other human beings is the source of our special responsibilities to them. In contrast to the four American principles of biomedical ethics - autonomy, nonmaleficence, beneficence, and justice - the four principles of European bioethics and biolaw include vulnerability along with autonomy, dignity, and integrity. According to, Jacob Dahl Rendtorff and Peter Kemp (I, 2000, p. 274) "the principle of vulnerability is ontologically prior to the other [European] principles, it expresses better than all of the other ethical principles ... the finitude of the human condition."

Some of the authors acknowledge both the difficulty of defining vulnerability and the importance of continued efforts to do so. The term "vulnerable populations" has its detractors, but . . . it captures significant aspects of marginalized groups" (II, Blacksher and Stone 2000, p. 421). Despite the different ways various guidelines define vulnerable research 
subjects, "vulnerability remains a useful concept, and the attempts to define it in regulations show that in fact we should regard every research subject as vulnerable until proved otherwise on an individual basis" (IV, Nicholson 2002, p. 20).

Each of the following sources includes some analysis of the concept of "vulnerability" or "vulnerable populations" applicable to medical research, healthcare, or bioethics. The guidelines chosen for Section $\mathrm{V}$ are those that specifically use the word "vulnerable" and stipulate the need for special protective measures for research involving vulnerable persons.

\section{General}

Alwang, Jeffrey; Siegel, Paul B.; and Jorgenson, Steen L. Vulnerability as Viewed from Different Disciplines. Presented at Sustaining Food Security and Managing Natural Resources in Southeast Asia: Challenges for the 21st Century. International Symposium. Chiang Mai, Thailand, 8-11 January 2002. Available at http://www.uni-hohenheim.de/symposium2002/p a_full/Full-Pap-S1-1_Siegel.pdf

According to the authors, the World Bank recognizes the need to define vulnerability in measurable and operational terms.

Policymakers and practitioners from different disciplines, including economics, sociology/anthropology, disaster management, environmental science, and health/nutrition, set standards for working with "at risk" or vulnerable populations and use diverse methods to benchmark vulnerability. Each discipline has its own reasons for defining and measuring vulnerability, consequently concepts, measures, and methods across the disciplines differ. Greater attempts at multidisciplinary cooperation regarding measurement of vulnerability must be made to improve risk management strategies.

Couser, G. Thomas. Vulnerable Subjects:
Ethics and Life Writing. Ithaca, NY: Cornell University Press, 2004.

Couser prefaces his book stating, "THIS IS NOT A BOOK ABOUT BIOETHICS" (p. ix).

It is, however, a book about making the vital relation between bioethics and life writing. It is about the ethics of representing vulnerable persons who are liable to exposure by someone with whom they have a trust-based relationship and are unable to represent themselves in writing. Because biomedicine involves such trust-based relationships, many of the stories here are those of the medically vulnerable. The bioethical principles of autonomy, nonmaleficence, and beneficence can be applied to life writing.

Goodin, Robert E. Protecting the Vulnerable: A Reanalysis of Our Social Responsibilities. Chicago, IL: University of Chicago Press, 1985. Goodin states that the vulnerability of other human beings is the source of our responsibility to them. Vulnerability can come as a natural and inevitable part of life or it can be created and sustained by social arrangements. We acknowledge special responsibility for the vulnerability of families and friends but we must also acknowledge our much broader moral responsibility to protect the vulnerable of society at large.

Kemp, Peter. Four Ethical Principles in Biolaw. In Bioethics and Biolaw, Volume II: Four Ethical Principles, ed. Peter Kemp, Jacob Rendtorff, and Niels Mattsson Johansen, pp.13-22. Copenhagen: Rhodos International Science and Art Publishers; and Centre for Ethics and Law in Nature and Society, 2000. Kemp introduces autonomy, dignity, integrity, and vulnerability as the four ethical principles of European bioethics and biolaw. He presents the principles not as rules for moral conduct, but as practical valuable aspects of the "good life." The principle of vulnerability recognizes the fragility of an intact but destructible totality and takes into account the biological, social, and cultural characteristics of human 
beings living in the modern technological world.

Macklin, Ruth. Bioethics, Vulnerability, and

Protection. Bioethics 17 (5-6): 472-86, October 2003.

Why is vulnerability a concern in bioethics? In order to answer this question, it is necessary to establish the criteria used to determine which individuals or groups are vulnerable, what counts as exploitation, and which efforts at protection may be paternalistic. Macklin confines her analysis of vulnerability to two areas: multinational research and culturally subordinated women.

Reich, Warren T. Prendersi cura dei vulnerabili: il punto d'incontro tra etica secolare ed etica religiosa nel mondo pluralistico [Taking Care of the Vulnerable: Where Religious and Secular Ethics Meet in a Pluralistic World]. Presented in Italian at Solenne Celebrazione Accademica in Occasione della Visita in Tretntino de Sua Santità il XIV Dalai Lama [Distinguished Lecture in Honor of the Dalai Lama], University of Trent, 2001. [Brochure] $35 \mathrm{p}$.

The moral, religious, and social pluralism of our post-Enlightenment world has led to a marginalization of religious ethics and a "dissatisfied restlessness within the community of scholars who are concerned with the language and ideas we use in proposing public policy regarding what is morally right for society" (p. 4). "Recently a 'new idea' has appeared in philosophy and bioethics that has the potential for challenging the agenda, the principles, the priorities, and the methods of applied ethics ... the idea of vulnerability" (p.10). The principle of vulnerability breaks through autonomy-driven bioethics that has virtually excluded human vulnerability and mutual care (p.14). Reich presents the concepts of vulnerability and care of the vulnerable as the grounds where religious and secular ethics meet.
Rendtorff, Jacob Dahl, and Kemp, Peter, and Commission of the European Communities. Biomedical and Health Research Programme, eds. Basic Ethical Principles in Bioethics and Biolaw, Volume I: Autonomy, Dignity, Integrity and Vulnerability. Copenhagen: Centre for Ethics and Law, and Barcelona: Institut Borja de Bioètica, 2000. 428 p.

The editors collected papers from the European Commission of the 1995-1998 BIO-MED II project identifying the basic ethical principles in European Bioethics and Biolaw: autonomy, dignity, integrity, and vulnerability. Of these four principles, "the principle of vulnerability is ontologically prior to the other principles, it expresses better than all other ethical principles in the discussion the finitude of the human condition, and therefore it might be the real bridging idea between moral strangers in a pluralistic society" (p.46). Within European biolaw, there is a growing consciousness of the need to protect the intrinsic dignity of particularly vulnerable populations, and in some European countries-Norway, Germany, France and Switzerland - there have been "very violent debates about the status of particularly vulnerable groups in relation to biomedical problems" (p. 274).

\section{Defining the Concept of Vulnerability}

Blacksher, Erika, and Stone, John R., eds.

Introduction to "Vulnerability" Issues of Theretical [sic] Medicine and Bioethics.

Theoretical Medicine and Bioethics 23 (6): 421-24, 2002.

Blacksher and Stone note that, until recently, bioethics largely has overlooked America's most vulnerable populations. The term vulnerable populations has its detractors, but the term also captures a significant aspect of marginalized groups. They emphasize that the poor health and diminished sense of dignity suffered by vulnerable populations are the results of unjust public policies and practices. 
Blacksher, Erika, and Stone, John R., eds.

[Special issue on vulnerability] Theoretical

Medicine and Bioethics 23 (6) 2002.

In this special issue, the editors highlight some important ethical issues involving vulnerable populations and some of the root causes of healthcare related vulnerability (p. 421). Erika Blacksher contributes two articles: the first, an introduction to vulnerability, and the second, a look at how socioeconomic deprivation can undermine the development of moral self and well-being. Alison M. Jaggar looks at women in the global South whose deteriorating health cannot be separated from their political and economic status. Nel Noddings considers the ethics of care as it relates to social policy toward the homeless. Ken Fox analyzes the case of a high-risk teen whose health inequities come as a result of race and class. John Stone looks at race and healthcare disparities experienced by African Americans. Lynn Pasquerilla addresses inclusion of inmates as human subjects in clinical trials.

\section{Brock, Dan W. Health Resource Allocation} for Vulnerable Populations. In Ethical Dimensions of Health Policy, ed. Marion Danis, Carolyn Clancy, and Larry R. Churchill, pp. 283-309. New York: Oxford University Press, 2002.

As a means of prioritizing allocation of health resources, Brock asks whether justice in health and healthcare should differentiate vulnerable populations from society at large or if just treatment should be derived from a general system of social justice. Brock goes on to discuss why this question has received relatively little attention to date in bioethics. He explores complexities in defining vulnerable populations and distinguishes three different moral categories of vulnerable populations: those whose conditions are caused by injustice, those whose conditions are caused by misfortune, and those who are at fault for their conditions. Bioethicists have much work to do on issues of healthcare resource prioritization and allocation.
Callahan, Daniel. The Vulnerability of the

Human Condition. In Bioethics and Biolaw, Volume II: Four Ethical Principles, ed. Peter

Kemp, Jacob Rendtorff, and Niels Mattsson

Johansen, pp.115-22. Copenhagen: Rhodos

International Science and Art Publishers; and

Centre for Ethics and Law in Nature and

Society, 2000.

Callahan notes that human beings are intrinsically vulnerable and, for this reason, the concept of vulnerability offers an interesting and potentially illuminating way of understanding not only many struggles of modern life in general but also of bioethics in particular (p. 115). Bioethics generally has tried to reduce or eliminate vulnerability but would do better to recognize it as part of the human condition and a necessary foundation of sustainable medicine (p.119). Dignity, worth, and autonomy are possible even in the presence of vulnerability.

Flanigan, Rosemary. Vulnerability and the Bioethics Movement. Bioethics Forum 16 (2): 13-18, Summer 2000.

Flanigan points out that, although the term "vulnerable populations" as a keyword descriptor was not officially introduced into the Bioethics Thesaurus until 1997, the bioethics movement historically has recognized that members of certain populations experience increased vulnerability within the healthcare system. Analyzing factors that make some individuals or some groups vulnerable and establishing policies for allied health professionals to counter vulnerability have become major bioethics projects of the new millennium. Flanigan argues that, in keeping with principles of beneficence and justice, bioethicists have an obligation to identify vulnerable populations and to secure their autonomy and dignity.

Fox, Ken. Hotep's Story: Exploring the Wounds of Health Vulnerability in the U.S. Theoretical Medicine and Bioethics 23 (6): 471-97, 2002. 
Human social enterprise produces human vulnerability. Social injustices like racism and socioeconomic marginalization give rise to preventable health inequities. Fox tells the story of Hotep, a high-risk teen from a Boston ghetto, and how his case, an intersection of race and class, exemplifies social construction of health vulnerabilities. Many vulnerabilities "would not exist if healthcare and other resources were delivered on the basis of need rather than on the basis of color, class, caste, or ability to pay" (p. 472).

\section{Kottow, Michael H. The Vulnerable and the}

Susceptible. Bioethics 17 (5-6): 460-71, October 2002.

Kottow makes the distinction between "vulnerability," the universal human condition of being intact but fragile, and "susceptibility," the condition of being biologically weak or diseased, with an increased predisposition toward additional harm. Vulnerability falls under the principle of justice, which affords equal protection to all members of society, whereas susceptibility is a determined state of destitution and must be specifically designated in order actively to apply social systems of targeted palliative treatment. Research has been slow to observe that all human subjects, especially those human subjects of research conducted in less developed countries, are susceptible. In making the appropriate distinctions between the vulnerable and the susceptible, researchers can avoid the use of practices that are ethically unacceptable in their home countries.

\section{Morawa, Alexander H. E. Vulnerability as a} Concept in International Human Rights Law. Journal of International Relations and Development 6 (2): 139-55, June 2003. Morawa states that there is no single approach to defining vulnerability. The term has no purposeful definition, yet it is a qualifying factor that can have concrete consequences in human rights litigation. Focusing on international human rights law and the adoption of specialized rights for vulnerable groups, Morawa analyses classification criteria and the consequences of such a classification.

\section{Rogers, Ada C. Vulnerability, Health and}

Health Care. Journal of Advanced Nursing 26: 65-72, July 1997.

Examining the word "vulnerability" in nursing literature, Rogers reveals a commonly used yet ill-defined concept in healthcare. Vulnerability is a matter of degree. It is situational and is greatly affected by personal perception. To determine vulnerability, nurses look to such factors as age, gender, race, ethnicity, social support, education, income, and life changes. Developing tools to measure vulnerability would improve prediction and prevention of health problems. Nurses could provide more holistic and comprehensive care with greater awareness of the sources of vulnerability.

\section{Shildrick, Margrit. Becoming Vulnerable:} Contagious Encounters and the Ethics of Risk. Journal of Medical Humanities 21 (4): 215-27, Winter 2000.

Shildrick writes that, in viewing the disabled body, we become threatened by our own vulnerability. "Body" and thus "self" become vulnerable to loss of a valued wholeness. We see disability as contagious, and we see the disabled person as something "other" and distinct from our secure self. From a feminist perspective, Shildrick asks what meaning vulnerability would have if we stepped back from the binary view of the "self" versus the "other" and reconfigured vulnerability from a term of weakness to a possibility of becoming.

\section{Spiers, Judith. New Perspectives on}

Vulnerability Using Emic and Etic

Approaches. Journal of Advanced Nursing 31

(3): 715-21, March 2000.

Spiers uses the anthropological terms "etic" (extrinsic) and "emic" (intrinsic) to clarify the concept of vulnerability in nursing. Through an etic approach, normative external 
evaluations and assumptions determine vulnerability, whereas, through an emic approach, the individual determines his or her own vulnerability and ability to respond to that vulnerability. Considering both etic and emic perspectives, nurses can challenge solely normative assumptions and bring new knowledge to the development of nursing and healthcare.

Thomasma, David C. The Vulnerability of the Sick. Bioethics Forum 16 (2): 5-12, Summer 2000.

"The principle of vulnerability can be stated this way: In human relations generally, if there are inequities of power, knowledge, or material means, the obligation is upon the stronger to respect and protect the vulnerability of the other, and not to exploit the less advantaged" (p. 7). Thomasma suggests that a special vulnerability of the sick should drive our healthcare commitments. The vulnerable in society need special protections, and these protections are developed by considering that vulnerability, not social contracts, establishes duty. Social policy should rest on objective treatment criteria for all individuals, regardless of class, social status, or disease (pp. 11-12).

\section{Vulnerability in Healthcare}

Aday, Lu Ann. At Risk in America: The Health and Health Care Needs of Vulnerable Populations in the United States. $2 \mathrm{~d}$ ed. San Francisco: Jossey-Bass Publishers, 2001. 372 p. Who are the vulnerable in America and why are they vulnerable? How many are there? Who pays for their healthcare and what programs and policies are needed? With these questions in mind, Aday looks at nine of America's vulnerable populations: high-risk mothers and infants; chronically ill and disabled individuals; persons living with HIV/AIDS; mentally ill and disabled persons; alcohol or substance abusers; individuals who are suicide or homicide prone; abusive families; homeless persons; and immigrants and refugees. Aday concludes that community-oriented health policies are essential to address the healthcare needs of vulnerable populations.

Appleton, Jane. The Concept of Vulnerability in Relation to Child Protection: Health Visitor's Perceptions. Journal of Advanced Nursing 20: 1132-40, December 1994.

As part of an effort to reduce health problems and increase child protection, many British National Health Service trusts provide health visitors to "vulnerable families." Appleton explores vulnerability as a nebulous concept used to allocate needed resources. Health visitors use checklists and other screening tools in an attempt to determine vulnerability objectively, yet ultimately their decisions are subjective. A striking feature of the findings of this study was the lack of consensus and clear definition of the commonly used term "vulnerability."

Botbol-Baum, Mylene. The Necessary Articulation of Autonomy and Vulnerability. In Basic Ethical Principles in Bioethics and Biolaw, Volume II: Partners Research, ed. Jacob Dahl Rendtorff; Peter Kemp; and Commission of the European Communities, Biomedical and Health Research Programme, pp. 57-64. Copenhagen: Centre for Ethics and Law, and Barcelona: Institut Borja de Bioètica, 2000.

Botbol-Baum argues that a tension exists between autonomy, often linked to judicial rights discourse within the clinical setting, and vulnerability, a term that is becoming increasingly present in bioethical discourse. Autonomy as a principle risks becoming a totalitarian attitude in situations where patients have lost capacity to make informed choices. On the other end, efforts to protect vulnerable patients who lack this capacity to make informed autonomous choices can be regarded as paternalistic. We must not dichotomize but balance autonomy and 
protection of the vulnerable.

Danis, Marion, and Patrick, Donald L. Health

Policy, Vulnerability, and Vulnerable

Populations. In Ethical Dimensions of Health

Policy, ed. Marion Danis, Carolyn Clancy, and

Larry R. Churchill, pp. 310-34. New York:

Oxford University Press, 2002.

"The term vulnerable populations suggests

that the characteristic of vulnerability is fixed and immutable"(p. 312). Almost everyone, however, will face poor health or disability at some point in life. Danis and Patrick argue that we should eliminate use of the label "vulnerable" or risk viewing those with the label as "other." Vulnerable others may be seen as objects of pity for their condition or as objects of resentment for their special access to health resources. The authors propose that health policy shift from conceptions of vulnerability to conceptions of risk stratification and that healthcare insurance coverage be required for all individuals through expansion of the Medicare program.

\section{Leight, Susan Bragg. The Application of a} Vulnerable Populations Conceptual Model to Rural Health. Public Health Nursing 20 (6): 440-48, November/December 2003.

Leight cites the Flaskerud and Winslow Vulnerable Populations Conceptual Model (IV, Flaskerud and Winslow 1998) to define vulnerable populations as social groups who have increased susceptibility to adverse health outcomes. Vulnerable populations have lesser resource availability, greater relative risk, and lower likelihood of health-seeking behaviors. Findings of the study support the application of the vulnerable populations model to rural communities. "Viewing rural health from the perspective of a vulnerable populations conceptual model holds much promise for future research, practice, and health policy initiatives" (p. 446).

McGovern, Thomas F. Vulnerability: Reflection on Its Ethical Implications for the
Protection of Participants in SAMHSA

Programs. Ethics and Behavior 8 (4): 293-304, 1998.

According to McGovern, the ethical principles and guidelines of Substance Abuse and Mental Health Services Administration programs reflect the vulnerability and right to dignity of its participants. Persons made vulnerable by conditions of mental illness or addictions require ethical guarantees that respect their sense of dignity. SAMHSA bases its protective guidelines upon the ethical principles of autonomy, beneficence and fairness. Guidelines take into consideration the individual, the institution and society. Programs for vulnerable individuals need a community focus if they are to be effective.

Reeder, Rachel, ed. [Special Issue on Vulnerable Populations]. Bioethics Forum 15

(2), Summer 1999. 56 p.

In this special issue, Reeder focuses on the plight of vulnerable populations and their inadequate access to healthcare. Robert D. Orr suggests that we go beyond justice to embrace the theological principles of mercy and grace, and rely more completely on the way medicine was prior to its secularization and commercialization. Alice Kitchen calls us to bridge gaps and deliver healthcare to non-English speaking immigrant populations. Tanya Whitehead suggests changes in training adults with developmental disabilities in order to balance power and encourage self-determination. Ellen Beck addresses health needs of the "underserved," those who for a variety of reasons lack access to healthcare. Robert Lyman Potter looks at prisoners as vulnerable persons unprotected from threats to health and dignity. Linda Johnson questions social initiatives to address the vulnerable status of children.

Reeder, Rachel, ed. [Special Issue on Vulnerability and the Bioethics Movement]. Bioethics Forum 16 (2), Summer 2000. 52 p. In her special issue, Reeder reflects on the 
"vulnerable other" and how the bioethics movement must advocate healthcare with respect to the dignity, autonomy, and vulnerability of all people. David Thomasma addresses practically and philosophically the difficult question of how society will provide healthcare to its most vulnerable populations. Rosemary Flanigan considers the relatively new concept of "vulnerable populations" within the field of bioethics and the obligation of bioethicists to correct injustices suffered by vulnerable populations through restoration of dignity and autonomy. Douglas McNair uses the example of end-stage heart failure to show the need for greater understanding of vulnerability and the need to develop population health policies respectful of all people. Valerie Yancey weighs hope and vulnerability and our moral responsibility to keep the balance tilted on the side of hope, reconciliation, and self-discovery.

\section{Shi, Leiyu. The Convergence of Vulnerable} Characteristics and Health Insurance in the U.S. Social Science and Medicine 53 (4): 519-29, August 2001.

Despite extensive research on healthcare efforts to reach vulnerable populations, there is no explicit consensus as to what constitutes vulnerability. Shi studies race, income, and self-perceived health status as indicators of vulnerability and examines the effects of these indicators on health insurance coverage. Results show vulnerability to be a matter of degree compounded by the presence of multiple vulnerability indicators. Of the three indicators, race and income most significantly predict lack of coverage. To reduce healthcare disparities, policymakers must allocate limited insurance resources to the most vulnerable.

Shi, Leiyu; Forrest, Christopher B.; von Schrader, Sarah; and Ng, Judy. Vulnerability and the Patient-Practitioner Relationship: The Roles of Gatekeeping and Primary Care Performance. American Journal of Public Health 93 (1): 138-44, January 2003.
Using race/ethnicity, socioeconomic status, and self-perceived health status as vulnerability indicators, the authors examine the extent to which gatekeeping arrangements and primary care experiences influence disparities in the physician-patient relationship among individuals with different levels of vulnerability. Factors that would improve relationships between practitioners and vulnerable patients include better access to healthcare and continuity of care.

Zaner, Richard M. Integrity and Vulnerability in Clinical Medicine: The Dialectic of Appeal and Response. In Bioethics and Biolaw, Volume II: Four Ethical Principles, ed. Peter Kemp, Jacob Dahl Rendtorff, Niels Mattsson Johansen, and Centre for Ethics and Law (Copenhagen, Denmark), pp. 123-40. Copenhagen: Rhodos International Science and Art Publishers, and Centre for Ethics and Law, 2000.

Zaner describes the experience of illness - one's own or that of another-as a confrontation with pain and a reminder of the eventuality of our own "not being" (p. 123). We are vulnerable. We need "to know" about our condition and to be cared for. Our trust is placed suddenly into an asymmetrical physician-patient relationship, a relationship in which the professional physician must be awakened to a moral sense not to take advantage of our vulnerability. "The phenomenon of vulnerability harbors the clue to professional integrity" (p. 124).

Zaner, Richard M. Power and Hope in the Clinical Encounter: A Meditation on Vulnerability. Medicine, Health Care and Philosophy: A European Journal 3 (3): 265-75, 2000.

Zaner draws an analogy between the conflicting ideals of the mythological Aesculapius and Gyges and the conflicting choice at the heart of the Hippocratic tradition: the choice whether to heal or to harm. The physician embodies power through knowledge, skills, resources, social legitimacy, 
authority, and the ultimate choice to act or not to act in behalf of the vulnerable patient. The role of the clinical ethicist is to mediate between power and vulnerability and, through dialogue, to balance the inherently asymmetrical physician-patient relationship.

\section{Vulnerability and Medical Research}

Backlar, Patricia. Human Subjects Research, Ethics, Research on Vulnerable Populations. In Encyclopedia of Ethical, Legal, and Policy Issues in Biotechnology, Volume 2, ed. Thomas H. Murray and Maxwell J. Mehlman, pp.641-51. New York: John Wiley \& Sons, 2000.

Vulnerable subjects generally are those who are cognitively impaired or subject to intimidation. Historically, the devalued vulnerable have served as unwitting subjects in research benefitting "privileged members of society" (p. 641). Codes have been implemented to protect vulnerable populations, but some efforts at protection have resulted in paternalistic practices or exclusion. Backlar looks at biomedical research as distinct from routine medical practice. "In order for research with vulnerable subjects to be ethically permissible, this difference should not only be clarified, but special procedural protections should also be employed" (p. 649). Protection should not mean exclusion but allowance to volunteer without fear of abuse.

Brody, Baruch A. Research on the Vulnerable Sick. In Beyond Consent: Seeking Justice in Research, ed. Jeffery P. Kahn, Anna C. Mastroianni, and Jeremy Sugarman, pp. 32-46. New York: Oxford University Press, 1998. Brody compares the old conceptualization of justice in research that emphasized protection of vulnerable subjects from being used without their consent and the new conceptualization that looks for a balance of access to benefits and protection from exploitation. For some patients, established therapies are not possible. They need to try new, experimental, and promising treatments despite risk. It is the combination of need, promise, and risk that makes these patients vulnerable. Justice in research with the vulnerable sick involves the balance of protection and access to new, needed therapies.

DeBruin, Debra. Reflections on

"Vulnerability." Bioethics Examiner 5 (2): 1, 4, 7; Summer 2001.

The Common Rule classifies certain groups as being especially vulnerable and therefore requiring additional protections. The term "vulnerable" is controversial for several reasons: Common Rule regulations do not define "vulnerability;" the list of vulnerable populations is illustrative but not exhaustive; the regulations are paternalistic in nature; and use of the term "vulnerable" has been viewed as demeaning and sexist. DeBruin argues that "the regulations ought not to speak of groups as being categorically vulnerable at all" (p. 4). The focus of human subject protection should be less on the concept of "vulnerability,"and more on the concepts of special risk and empowerment.

Farber, Neil J.; Aboff, Brian M.; DeJoseph, Maria R.; Castellano, Jerry; Weiner, Joan; and Boyer, E. Gil. Physicians' Understanding of Consent Requirements for Phase I Clinical Trials in Cognitively Impaired or Highly Vulnerable Patients. Accountability in

Research 11 (1): 63-78, January-March 2004. The authors investigated attitudes of United States physicians about entering into Phase I clinical trials patients who cannot give informed consent or who are identified as members of a vulnerable population. The questionnaire asked respondents whether they approved of enrolling 10 hypothetical patients of a vulnerable population, who could not give informed consent and had no family member or guardian to decide on their behalf. Some physicians condoned enrollment. Greater efforts need to be made to educate physicians 
on ethical issues and federal guidelines.

Flaskerud, Jacquelyn H., and Winslow, Betty J.

Conceptualizing Vulnerable Populations Health-Related Research. Nursing Research 47 (2): 69-78, March/April 1998.

"Vulnerable populations are social groups who experience limited resources and consequent high relative risk for morbidity and premature mortality" (p. 1). Flaskerud and Winslow present a vulnerable populations conceptual framework proposing that society as a whole is responsible for providing the opportunities and resources needed to reduce vulnerability and maintain community health. Community health programs should work in collaboration with other community resource and information programs to empower vulnerable populations to be active partners in the maintenance of their own health.

Kipnis, Kenneth. Vulnerability in Research Subjects: A Bioethical Taxonomy. In Ethical and Policy Issues in Research Involving Human Participants, Volume II: Commissioned Papers and Staff Analysis, ed. [United States] National Bioethics Advisory Commission, pp. G1-13. Bethesda, MD: National Bioethics Advisory Commission, 2001.

The term "vulnerable" seems to have been grandfathered into the literature of research ethics without certification or agreed-upon standards. Kipnis provides an overview and analysis of the concept of vulnerability with a functional taxonomy divided into six discrete types of vulnerabilities, intended to be exhaustively applicable to research subjects: cognitive, juridic, deferential, medical, allocational, and infrastructural.

Kopelman, Loretta. Research Policy: Risk and Vulnerable Groups. In Encyclopedia of Bioethics, 3d ed., ed. Stephen G. Post, pp. 2365-72. New York: Macmillan, 2004. In the Encyclopedia of Bioethics section on Research Policy, Kopelman addresses risks that confront researchers working with vulnerable subjects. Vulnerable subjects are those who are unable to give informed consent or are likely to be coerced. Researchers face risks associated with both inclusion and exclusion of vulnerable groups. Inclusion in research where guidelines provide inadequate protections opens the risk of exploitation. Exclusion limits access to experimental treatments. Ethical review committees play a key role in efforts to achieve the balance of protection and access.

London, Leslie. Ethical Oversight of Public Health Research: Can Rules and IRBs Make a Difference in Developing Countries? American Journal of Public Health 92 (7): 1079-84, July 2002.

London sees the concept of vulnerability as key to addressing the challenges of ethical review in international research, particularly for developing countries. However, typically the focus on vulnerability has ignored the agency of vulnerable subjects. The IRB process of "speaking for others" in relation to vulnerable populations minimizes the mutuality of the researcher-subject relationship. International review processes must develop new ways to strengthen agency and autonomy, thereby empowering "vulnerable" research subjects to be initiators and negotiators in their own health.

Nicholson, Richard. Who is Vulnerable in Clinical Research? [reprint]. Bulletin of Medical Ethics 181: 19-24, September 2002. "Even if not explicit, Vulnerability as a concept has been implicit since the earliest attempts to regulate medical research" (p. 19). Looking at some historical international guidelines, from the Prussian regulation of 1900 through the 2002 regulations of the Council for International Organizations of Medical Sciences (CIOMS), the term has been defined in such different ways that almost every research subject could be labeled vulnerable. Nicholson argues that, despite its vagueness, "vulnerability remains a useful 
concept, and the attempts to define it in regulations show that we should in fact regard every research subject as vulnerable, unless and until proven otherwise on an individual basis" (p. 20).

Stone, T. Howard. The Invisible Vulnerable: The Economically and Educationally Disadvantaged Subjects of Clinical Research. Journal of Law, Medicine and Ethics 31 (1): 149-53, Spring 2003.

The Common Rule related to human research recognizes the vulnerability of persons who are economically or educationally disadvantaged. All groups classified here as vulnerable are considered susceptible to coercive or undue influence. Despite acknowledged vulnerability, and unlike other groups listed as vulnerable, the economically and educationally disadvantaged are accorded no specific additional protections. Stone addresses the need for a new subpart under the Common Rule, clearly stating protections for the economically and educationally disadvantaged. Without added protections they remain the "invisible vulnerable."

Weijer, Charles. Research Involving the Vulnerable Sick. Accountability in Research 7 (1): 21-36, 1999.

Researchers and Institutional Review Boards (IRBs) must identify patients who are sufficiently vulnerable to require protections above and beyond those available for all research subjects. The task of defining vulnerability, deciding who among the sick are vulnerable, determining available and appropriate protections and the amount of risk the sick may be exposed to in research are matters of judgment. Weijer considers three contemporary controversies on research with the vulnerable sick: psychiatric patients and placebo-controlled trials; Phase I oncology trials; and research on incompetent patients in the emergency room.

\section{Guidelines On Medical Research With}

\section{Vulnerable Populations}

Council for International Organizations of Medical Sciences (CIOMS), and the World Health Organization. International Ethical Guidelines for Biomedical Research Involving Human Subjects. Geneva, Switzerland, 2002. [Available at http://www.\%20cioms.ch/ frame_guidelines_nov_\%202002.htm] Regarding research involving vulnerable persons, CIOMS proposes that "Special justification is required for inviting vulnerable individuals to serve as research subjects and, if they are selected, the means of protecting their rights and welfare must be strictly applied" (Guideline 13).

\section{International Summit Conference on} Bioethics Towards an International Ethic for Research Involving Human Subjects. Summary Report. Issued at Ottawa, Canada: 1987. In Encyclopedia of Bioethics, $3 \mathrm{~d}$ ed., ed. Stephen G. Post, pp. 2843-47. New York: Macmillan 2004.

Regarding research with those with restricted ability to give consent, the report states: "The overriding purpose of ethics review is the protection of the research subjects. An essential component of this protection, enunciated in all international codes of ethics is that each research subject must consent freely, and with full information, to participate in the research. However, those who are legally incompetent cannot, by definition, give their consent. Delegates focused their discussion of this issue on research with children, while recognizing that similar concerns arise with adults who are mentally handicapped and with other vulnerable populations" (Article 5).

United States. Department of Health and Human Services. Protection of Human Subjects (45 CFR 46), 13 November 2001. [Available at http://ohsr.od.nih.gov/guidelines/45cfr46.html] According to 45 CFR 46, Vulnerable Research Subject Categories include children; prisoners; 
pregnant women; and handicapped, mentally disabled, economically disadvantaged, or educationally disadvantaged persons. "If an IRB regularly reviews research that involves a vulnerable category of subjects, consideration shall be given to the inclusion of one or more IRB members knowledgeable about and experienced in working with these subjects. Selection of subjects must be equitable and particularly cognizant of the special problems of research involving vulnerable populations. And when subjects are likely to be vulnerable to coercion or under influence, additional safeguards must be included in the study to protect the rights and welfare of these subjects" (45 CFR 46. Subpart A§46.107[a]).

United States. National Commission for the Protection of Human Subjects of Biomedical and Behavioral Research. The Belmont Report: Ethical Principles and Guidelines for the Protection of Human Subjects of Research. 18 April 1979. [Available at http://ohsr.od.nih.gov/ guidelines/belmont.html]

"When vulnerable populations are involved in research, the appropriateness of involving them should itself be demonstrated. A number of variables go into such judgments, including the nature and degree of risk, the condition of the particular population involved, and the nature and level of the anticipated benefits" (Part C. Applications: 2.iv).

World Medical Association General Assembly.
Declaration of Helsinki: Ethical Principles for Medical Research Involving Human Subjects. June 1964. [Available at http://www.wma.net/e/ policy/b3.htm].

"Medical research is subject to ethical standards that promote respect for all human beings and protect their health and rights.

Some research populations are vulnerable and need special protection. The particular needs of the economically and medically disadvantaged must be recognized. Special attention is also required for those who cannot give or refuse consent for themselves, for those who may be subject to giving consent under duress, for those who will not benefit personally from the research and for those for whom the research is combined with care" (Article 8).

Mary C. Ruof, M.L.I.S., is a Reference Librarian, National Reference Center for Bioethics Literature, Georgetown University, Washington, DC.

Produced at the National Reference Center for Bioethics Literature, Kennedy Institute of Ethics, Georgetown University, Box 571212, Washington, DC 20057-1212. The Center operates on a contract with the National Library of Medicine, National Institutes of Health. Additional support is provided by the National Center for Human Genome Research, National Institutes of Health, and by other public and private sources. 